\title{
PENGARUH LATIHAN BEBAN BOTOL BERPASIR TERHADAP KEMAMPUAN SERVICE ATAS SISWI PESERTA EKSTRAKURIKULER BOLA VOLI DI SMPN 8 KOTA BENGKULU
}

\author{
Perdian Sutianto \\ PENJAS FKIP UNIB, E-mail : perdiansutianto0102@gmail.com \\ Syafrial, \\ Universitas Bengkulu \\ Sofino \\ Universitas Bengkulu
}

\begin{abstract}
Abstrak
Penelitian ini bertujuan untuk mengetahui peningkatan service atas setelah diberikan penerapan latihan beban botol berpasir pada siswi ekstrakurikuler bola voli di SMPN 8 Kota Bengkulu. Metode yang digunakan dalam penelitian ini adalah metode eksperimen. Dengan sampel yang berjumlah 30 orang, dengan desain yang digunakan adalah Pre test-post test group design. Instrumen penelitian ini untuk mengetahui peningkatan service atas dengan menggunakan tes dan pengukuran.Teknik analisis data menggunakan uji t. Hasil peneliti ini diperoleh $t_{\text {hitung }} 17,7053$ jika dibandingkan dengan $t_{\text {tabel }} 1$ 1,699, maka nilai $t_{\text {hitung }}>$ $t_{\text {tabel }}$ berarti ada pengaruh yang signifikan dari latihan beban botol berpasir terhadap kemampuan service atas siswi ekstrakurikuler bola voli di SMPN 8 Kota Bengkulu.
\end{abstract}

Kata Kunci : Botol berpasir, Servis atas.

\begin{abstract}
This study aims to determine the improvement of service after being given the application of weight training of sandy bottles on students extracurricular volleyball in SMPN 8 Kota Bengkulu. The method used in this research is the experimental method. With a sample of 30 people, the design used is Pre testpost test group design. The instrument of this research is to know the improvement of service by using test and measurement. Data analysis technique use $t$ test. The result of this research is obtained tcount 17,7053 when compared with ttable 1,699, hence tcount value $>$ ttable means there is significant influence from weight training of sandy bottle to service ability of voluptuous extracurricular student in SMPN 8 KotaBengkulu.
\end{abstract}

Keywords: Sandy Bottle Load, Top Service. 


\section{PENDAHULUAN}

Pendidikan adalah suatu hak yang wajib diberikan dan di terima oleh seluruh masyarakat di indonesia, untuk mengembangkan potensi dirinya, untuk memiliki kekuatan spiritual keagamaan, pengendalian diri, kepribadian, kecerdasan, akhlak mulia serta keterampilan yang ada didalam diri seseorang. Untuk mengembangkan kekuatan spritual (keagamaan), pengendalian diri , kepribadian, kecerdasan, akhlak mulia serta keterampilan yang ada bisa dikembangkan melalui pendidikan jasmani karena di pendidikan jasmani terdapat 3 aspek yaitu : 1) aspek kognitif, 2) aspek afektif, dan 3) aspek psikomotor. Pendidiikan jasmani di sekolah pada umumnya ada kegiatan belajar kurikulum dan kegiatan belajar di luar jam kurikulum (ekstrakurikuler). Di SMPN 8 Kota Bengkulu ada banyak ekstrakurikuler yang ditawarkan kepada siswa/i agar bisa mengembangkan bakat kepribadian yang mereka miliki, Olahraga bola voli adalah salah satu cabang olahraga yang sangat digemari karna tidak kontak fisik, sehingga kemungkinan cedera relatip kecil, Dalam permainan bola voli, ada beberapa teknik dasar yang harus diketahui dan dikuasai oleh para pemain yaitu :1) passing 2) smash 3) service dan 4) blocking Penguasaan teknik ini penting dipahami agar seseorang bisa bermain voli dengan baik dan benar. Penguasaan teknik ini bisa didapatkan melalui proses berlatih secara benar dan terarah. Salah satu betuk teknik permainan bola voli yang penulis maksud adalah service khususnya service atas.

Service atas adalah pukulan atau serangan pertama untuk bermain bola voli, service modal awal bagi sebuah tim. Sehingga apabila seseorang pemain gagal melakukan service dengan baik, maka akan merugikan bagi tim. Dalam melakukan service atas sangat memerlukan kekuatan otot, kekuatan otot lengan disini sangat diperlukan, jika seseorang memiliki kekuatatan otot lengan maka service atas akan keras, terarah dan melewati net voli. Berdasarkan hasil observasi awal yang dilakukan peneliti pada 15 Desember 2017, ditemukan ketika melakukan Service atas masih banyak siswi yang belum bisa melakukan teknik service atas yang baik, kebanyakan siswi melakukan service atas dengan teknik yang salah, disini juga tidak adanya program latihan khusus untuk service atas, masih lemahnya otot lengan siswi ekstrakurikuler untuk melakukan service atas, dan para pelatih juga kurang memahami latihan beban, sedangkan latihan beban salah satu cara untuk menguatkan otot lengan agar siswi mampu melakukan service atas. Sedangkan kita tahu untuk menjadi pemain voli yang baik, individu harus menguasahi teknik dasar yang baik. Dari masalah di atas maka peneliti tertarik meneliti "Pengaruh Latihan Beban Botol Berpasir Terhadap Peningkatan Kemampuan Service Atas Siswi Peserta Ekstrakurikuler di SMPN 8 Kota Bengkulu". Rumusan masalah "Apakah ada pengaruh latihan beban botol berpasir dengan kemampuan service atas dapat meningkatkan kemampuan pada siswi ekstrakurikurikuler bola voli SMPN 8 Kota Bengkulu ?"

\section{METODE}

Desain Penelitian

Berdasarkan judul di atas maka penelitian ini termasuk dalam penelitian kuasi eksperimen. Penelitian ini dibagi menjadi 3 tahapan yakni, pretest, treatment, dan post test. Desain yang digunanakan adalah Pre test-post test group design, Dian dan Bayu (2013:34-35). Tempat dan Waktu Penelitian

Tempat penelitian berlangsung di SMPN 8 Kota Bengkulu.Waktu penelitian 
ini dilakukan selama 16 kali pertemuan terhitung dari dikeluarkannya surat izin meneliti hingga batas waktu ditentukan.

Populasi Penelitian Dan Sampel

Populasi dalam penelitian ini adalah seluruh siswi aktif peserta ektrakurikuler bola voli di SMPN 8 Kota Bengkulu berjumlah 30 orang.

Dalam penelitian ini menggunkan total sampling. Artinya seluruh siswi menjadi sampel berjumlah 30 orang.

Variabel Penelitian

Variabel adalah segala sesuatu yang berbentuk apa saja yang ditetapkan oleh peneliti untuk dipelajari sehingga diperoleh informasi oleh hal tersebut, kemudian di tarik kesimpulanya. Sugiyono, (2006:42) Dalam penelitian ini terdapat dua variabel yaitu variabel bebas dan variabel terikat.

Variabel Bebas

Variabel bebas adalah variabel yang mempengaruhi variabel lain disebut variabel penyebab atau Independent Sugiyono, (2006:42) Variabel bebas dalam penelitian ini adalah latihan beban botol berpasir.

Variabel Terikat

Variabel terikat adalah variabel yang di pengaharuhi atau yang menjadi akibat dari variabel bebas. Sugiyono, (2006:42) variabel terikat dalam penelitian ini adalah kemampuan servis atas siswi ektrakurikuler bola voli di SMPN 8 Kota Bengkulu.

Teknik Pengumpulan Data

Teknik pengumpulan data adalah teknik atau cara yang dilakukan untuk mengumpulkan data. (Supardi,2017:110). Untuk mendapatkan data dalam penelitian ini menggunakan tes kemampuan servis atas

Instrumen Penelitian

Instrumen penelitian adalah suatu alat yang digunakan mengukur fenomena alam maupun sosial yang di amati, secara spesifik semua fenomena ini disebut variabel penelitian. Sugiyono, (2006:114). Rima Febrianti (2016:54) pada penelitian ini menggunakan instrumen Tes dan Pengukuran.

Berikut pelaksanaan tes kemampuan servis:

1. Tujuan

: Menilai Untuk mengukur kemampuan dalam melakukan servis atas.

2. Perlengkapan : Lapangan bola voli, net, bola, catatan.

3. Prosedur

$$
\begin{aligned}
& \text { : Peserta berdiri di } \\
& \text { daerah servis dan } \\
& \text { melakukan servis atas } \\
& \text { sebanyak } 6 \text { kali, dan } \\
& \text { Peserta dianjurkan } \\
& \text { untuk mengarahkan } \\
& \text { bola pada area sasaran } \\
& \text { nilai tertinggi }
\end{aligned}
$$

\section{Penilaian : Besarnya nilai sesuai dengan jatuhnya bola pada sasaran angka 1 , 2, 3, 4, dan 5. Bila bola yang jatuh di garis batas akan diberikan nilai pada sasaran yang lebih tinggi, misalnya antara angka 2 dan 3, maka dihitung dengan nilai 3.}

Gambar 1 Tes Kemampuan Servis Atas

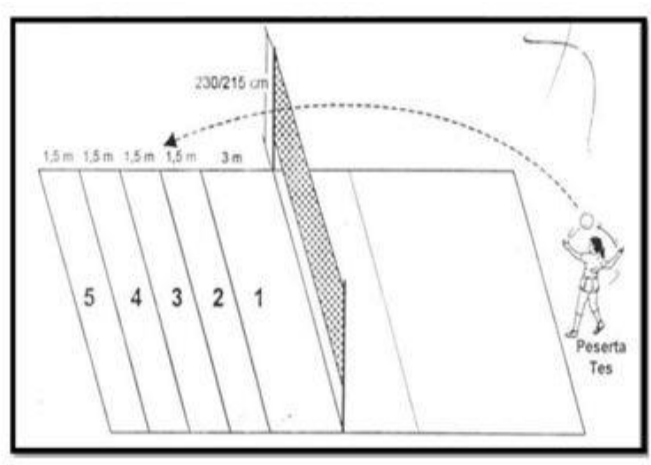


Penilaian hasil servis atas dilakukan dengan berpedoman seperti pada tabel dibawah ini

Tabel 1. Norma Penilaian

\begin{tabular}{|c|c|c|c|}
\hline NO & Putra & Putri & Katagori \\
\hline 1 & $>27$ & $>23$ & $\begin{array}{c}\text { Baik } \\
\text { Sekali }\end{array}$ \\
\hline 2 & $21-$ & $\begin{array}{c}18- \\
22\end{array}$ & Baik \\
\hline 3 & $\begin{array}{c}15- \\
26\end{array}$ & $\begin{array}{c}11- \\
17\end{array}$ & Cukup \\
& 20 & $8-$ & Kurang \\
\hline 4 & $8-$ & $7-$ & \\
\hline 5 & $<7$ & $<6$ & $\begin{array}{c}\text { Sangat } \\
\text { Kurang }\end{array}$ \\
\hline
\end{tabular}

Teknik Analisa Data

Uji Normalitas

Tujuan uji normalitas data adalah untuk mengetahui apakah distribusi data mengikuti atau mendekati distribusi normal atau mempunyai pola seperti distribusi normal. (Supardi, 2017:173).Uji normalitas menggunakan rumus Liliefors dengan rumus :

berikut :

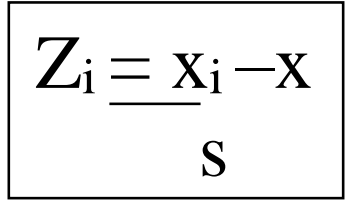

Jika $\mathbf{L}^{\text {hitung }} \leq \mathbf{L}^{\text {tabel }}$ artinya data berdistribusi normal dan jika sebaliknya data tersebut tidak berdistribusi normal.

\section{Uji Homogenitas}

Uji homogenitas menggunakan uji $\mathbf{F}$ dengan rumus sebagai berikut :

$$
\mathrm{F}=\frac{\mathrm{V}^{\text {terbesar }}}{\mathrm{V}^{\text {terkecil }}}
$$

Dengan kriteria sebagai berikut :

Jika $\boldsymbol{F}_{\text {hitung }} \leq \mathbf{F}_{\text {tabel }}$ maka data homogen dan sebaliknya maka data tidak homogen Pengujian Hipotesis

Uji hipotesis digunakan untuk mengetahui ada atau tidaknya pengaruh dari latihan beban botol berpasir. Untuk menguji hipotesis dalam penelitian ini menggunakan uji t sampel sejenis. Uji $t$ sampel sejenis dimaksudkan bahwa distribusi data yang dibandingkan berasal dari kelompok subjek yang sama.

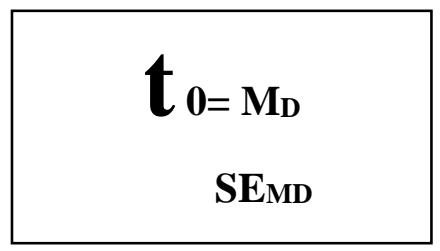

Dengan kriteria sebagai berikut :

t hitung $>\mathrm{t}$ tabel berarti signifikan

$\mathrm{t}$ hitung $<\mathrm{t}$ tabel tidak signifikan

Penelitian ini adalah usaha dalam melakukan segala sesuatu untuk mengisi kekosongan atau kekurangan yang ada, menggali lebih dalam apa yang telah ada,.Penelitian ini merupakan penelitian deskriptif kuantitatif yang mengambarkan situasi atau keadaan yang sedang berlangsung dengan melakukan tes.Penelitian deskriptif merupakan jenis penelitian untuk memberi uraian mengenai fenomena atau gejala sosial yang diteliti dengan mendeskripsikan tentang nilai variable mandiri, baik satu variable atau lebih (independent) berdasarkan indikator- indikator dari variabel yang diteliti tanpa membuat perbandingan atau menghubungkan antara variabel yang diteliti guna untuk eksplorasi dan klasifikasi dengan mendeskrifsikan sejumlah variabel yang berkenaan dengan masalah variabel yang diteliti Iskandar (2010:61).Tempat dan Waktu Penelitian

1. Tempat Penelitian

Penelitian ini dilakukan di lapangan SMP N 18 Kota Bengkulu.

\section{WaktuPenelitian}

Penelitian ini di lakukukan selama 1 bulan terhitung sejak tanggal 10 April - 5 Mei 2018. Menurut Dewi Laelatul Badriah (2006:80) Populasi penelitian dalam penelitian sosial, populasi didefenisikan 
sebagai kelompok subyek yang hendak dikenai generalisasi hasil penelitian.Dalam penelitian ini yang menjadi populasi adalah seluruh siswa ekstrakurikuler bola voli SMP N 18 Kota Bengkulu yang berjumlah 30 orang siswa putra.MenurutDewiLaelatulBadriah (2006:81)

Sampeladalahsebagiandaripopulasi, karenaiamerupakanbagiandaripopulasiten tulahiamemilikiciri-ciri yang dimilikiolehpopulasinya.

Dimanapadapenelitianinisampelnyaseban yak $\quad 30 \quad$ siswa yang mengikutiekstrakurikuler bola voli di SMP N 18 Kota Bengkulu. Pengumpulan data adalah prosedur yang sistematis dan standar untuk memperoleh data yang diperlukan, juga dijelaskan prosedur pengambilan data sehinga dapat berjalan dengan baik dan lancar. Adapun teknik pengumpulan data dalam tes meningkatkan kemampuan open spike dalam bermain bola voli :1. Observasi

2.Wawancara 3. Tes 4. Dokumentasi. Dokumentasi dilakukan dengan tujuan untuk memperoleh data berupa tertulis, foto, dan gambar untuk kepentingan kevalitan data penelitian. Instrumen penelitian adalah alat atau tes yang digunakan untuk mengunakan data guna mendukung dalam keberhasilan suatu penelitian.Instrumen dalam penelitian ini dibuat atau dimodifikasi untuk mengukur kemampuan siswa secara individu bukan beregu.Tes yang dilakukan adalah tes ketepatan (spike) yaitu tes memukul bola dengan mengarahkan bola ketempattempat yang telah di beri nilai atau skor.Tujuan tes open spike untuk mengetahui kemampuan peserta tes dalam melakukan open spike secara baik.

1. Alat-alat yang digunakan untuk mengukur kemampuan open spike, sebagai berikut : lapangan, bola voli, net, catatan, pluit.
2. Pelaksanaan tesa. Sebelum melakukan tes, alat dipersilakan untuk melakukan percobaan smash sebanyak 2 kali.

a. Siswa melakukan smash sebanyak 10 kali

b. Siswa melakukan smash dengan cara melempar bola sendiri.

c. Posisi untuk melakukan smash di tengah (posisi 3).

d. Net di modifikasi.

3. Penilaian

a. Penilaian sesuai dengan jatuhnya bola di daerah sasaran.

b. Bola menyangkut di net dan keluar lapangan (out) diberinilai 0 .

c. Nilai yang diperoleh adalah skor total dari 10 kali smash yang dilakukan.

Tabel 2. Norma Tes Ketepatan spike

\begin{tabular}{|c|c|c|}
\hline NO & Kriteria & Skor \\
\hline 1 & Sangat baik & $>33$ \\
\hline 2 & Baik & $28-32$ \\
\hline 3 & Cukup & $23-27$ \\
\hline 4 & Sedang & $18-22$ \\
\hline 5 & Kurang & $13-17$ \\
\hline 6 & SangatKurang & $<12$ \\
\hline
\end{tabular}

TeknikAnalisis Data, Teknik analisis data yang digunakan dalam penelitian ini adalah analisis deskriptif kuantitatif, analisis data yang digunakan menggunakan deskriptif kuantitatif dengan persentase. 
Setelah semuanya diperoleh data diolah menggunakan statistik deskriptif dengan cara hanya mendeskripsikan hasil temuan yang di peroleh dari pengukuran tes open spike. Dengan rumus Sudjana.

Rumus statistik sederhana :

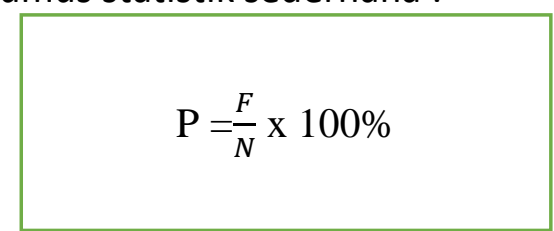

\section{HASIL DAN PEMBAHASAN \\ Hasil}

Deskriptif Data

Penelitian ini dimaksudkan untuk mengetahui ada tidaknya pengaruh latihan beban botol berpasir terhadap hasil Service atas siswi peserta ekstrakurikuler bola voli SMP Negeri 8 Kota Bengkulu, Untuk mengetahuinya sebelum siswi diberikan perlakuan (treatment), siswi diberikan tes awal terlebih dahulu yaitu dengan cara melakukan service atas sebanyak 6 kali, setelah diberi tes awal barulah siswi ekstrakurikuler bola voli diberi perlakuan (treatment) yaitu latihan beban botol berpasir sebanyak 16 kali pertemuan, setelah diberi perlakuan maka siswi ekstrakurikuler bola voli diberikan tes akhir dengan cara melakukan service atas sebanyak 6 kali.

\section{Diagram Hasil kemampuan pretes- postest servis atas}

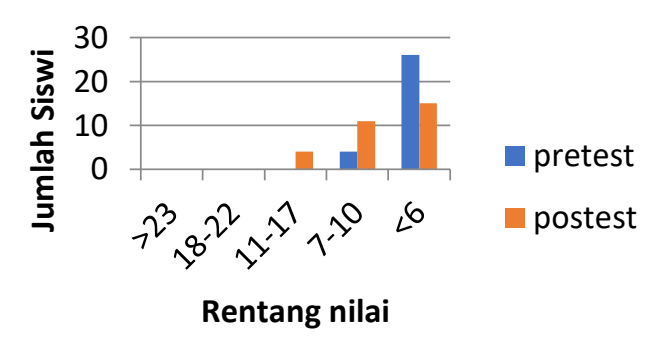

\begin{tabular}{|c|c|c|c|c|}
\hline $\mathbf{N}$ & Rentan \\
g Nilai & $\begin{array}{c}\text { Keterang } \\
\text { an }\end{array}$ & $\begin{array}{c}\text { Freku } \\
\text { ensi } \\
\text { Pretes } \\
\boldsymbol{t}\end{array}$ & $\begin{array}{c}\text { Frekue } \\
\text { nsi } \\
\text { Posttes } \\
\boldsymbol{t}\end{array}$ \\
\hline 1 & $>23$ & $\begin{array}{c}\text { Sangat } \\
\text { Baik }\end{array}$ & - & - \\
\hline 2 & $18-22$ & Baik & - & - \\
\hline 3 & $11-17$ & Cukup & - & 4 Orang \\
\hline 4 & $7-10$ & Kurang & 4 & $\begin{array}{c}11 \\
\text { Orang }\end{array}$ \\
\hline 5 & $<6$ & $\begin{array}{c}\text { Sangat } \\
\text { Kurang }\end{array}$ & $\begin{array}{c}26 \\
\text { Orang }\end{array}$ & $\begin{array}{c}15 \\
\text { Orang }\end{array}$ \\
\hline & \multicolumn{4}{|c|}{ Terlihat pada diagram pretest } \\
\hline
\end{tabular}

masih banyak sekali siswi yang nilai nya sangat kurang baik, Lalu peneliti memberikan perlakuan latihan beban botol berpasir selama 16 kali pertemuan, setelah diberikan treatmen, Peneliti melakukan tes akhir (Posttest) terlihat lah dari dari diagram perubahan hasil nilai siswi. Setelah semua siswi melaukan tes akhir maka peneliti menganalisis data yang ada, dari hasil penelitian di dapat hasil nilai rata-rata pre test sebesar 3,7 dan nilai hasil rata-rata post test 7,17.

Uji Prasyarat.

Sebelum analisis data dilakukan, maka perlu dilakukan uji persyaratan analisis yaitu dengan uji normalitas dan uji homogenitas. Hasil uji prasyarat dan uji hipotesis dapat dilihat sebagai berikut:

Penghitungan Normalitas

Penghitungan normalitas bertujuan untuk mengetahui apakah sampel dari populasi yang berdistribusi normal. Penghitungan uji normalitas dengan menggunakan rumus Liliefors. Hasil yang diperoleh adalah :

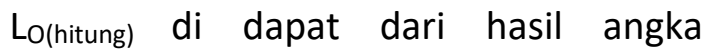
terbesar dari $\mathrm{FZ}_{1}-\mathrm{SZ}_{1}$. Di dapatlah $\mathrm{Lo}$ (hitung) tes awal = 0,153185 dan $\mathrm{L}_{\text {(hitung) }}$ tes akhir = 0,157496 , Ltabel di dapat dari $n=30 L_{\text {tabel }}=$ 0,161 dari tabel di atas $L_{o(h i t u n g)}<L_{\text {tabel, }}$ berdistribusi Normal. 


\section{Uji Homogenitas}

Uji homogenitas berguna untuk menguji kesamaan beberapa sampel, yaitu seragam atau tidak varians sampel di ambil dari populasi.Uji homogenitas menggunakan uji $F$ dengan derajat kebebasan dan taraf signifikansi a=0,05 pada table berdistribusi $F$.

nilai $F_{\text {hitung }}=1,699$ sedangkan nilai $f$ table pada taraf signifikan $a=0,05, d k=n-1=$ 30-1=29 di dapatlah $F_{\text {tabel }}$ sebesar 1,84. jadi. Fhitung $1,699<F_{\text {tabel }} 1,84$, berarti tidak terdapat perbedaan dari masing-masing variabel atau harga variansya Homogen.

Uji Hipotesis

Setelah dilakukan penghitungan normalitas dan homogenitas, selanjutnya dilakukan pengujian hipotesis menggunakan uji-t sebagai berikut : hipotesis mengatakan ada pengaruh latihan botol berpasir terhadap service atas pada siswi ekstrakurikuler bola voli di SMPN 08 Kota Bengkulu. Dari hasil data yang terkumpul maka penghitungan menunjukan $t_{\text {hitung }}$ sebesar $17,7053>t_{\text {table }}$ $=1,699$. Berarti signifikan.

Selanjutnya hipotesis mengatakan selanjutnya ada pengaruh latihan beban botol berpasir terhadap kemampuan service atas siswi ekstrakurikuler bola voli di SMPN 08 Kota Bengkulu, diterima. Dengan demikian siswi yang mendapatkan nilai latihan botol berpasir mengalami peningkatan pada servis atas.

Service adalah pukulan bola yang dilakukan dari belakang garis akhir lapangan permainan melampaui net daerah lawan. Untuk memproleh kemampuan servis atas yang baik seseorang pemain harus di dukung oleh latihan agar servisnya sampai pada daerah lawan dan mematihkan, kelemahan dari dari servis atas biasanya seseorang pemain yang tidak mempunyai kekuatan otot lengan tidak akan sampai dalam melintasi net dan bahkan mudah diterima oleh lawan. untuk meningkan kekuatan otot lengan tersebut maka dapat dilakukan dengan metode latihan yang efektif salah satunya dengan cara metode latihan beban.

Metode latihan beban merupakan salah satu cara pemantapan kondisi yang melibatkan gerakan yang berulang-ulang dengan beban yang submaksimal. Menurut Sadoso Sumosardjuno dalam Turas Rio Anggoro, (2016 : 37) Dalam penelitian ini latihan beban berfungsi untuk menguatkan otot lengan menggunakan latihan beban botol bepasir.

Kelebihan beban botol berpasir dari pada beban dumbbell yaitu mudah di dapat, mudah dibuat, berat bisa di variasikan sesuai dengan kemampuan siswi tersebut dan botol berpasir ini mudah untuk di dapat karena bahan pembuatanya mudah di dapatkan, bahan pembuatannya cukup dari bekas-bekas botol lalu di isikan pasir, di bandingkan dengan beban dumbbell yang ada di tokotoko olahraga selain dengan harganya cukup mahal dan berat beban tidak bisa di tentukan sesuai kemampuan siswi

Latihan beban botol berpasir yang dilakukan secara kontinyu berfungsi meningkatkan kerja otot lengan yang mana penambahan dapat menambah kekuatan otot lengan, sehingga dengan bertambahnya otot lengan maka secara tidak langsung kemampuan siswi dalam melakukan servis atas dapat bertambah.Kekuatan pada lengan sangatlah penting di karnakan dapat meningkatnya kekuatan dalam memukul bola dan akan mebuat jauhnya servis yang melampaui net, latihan yang dilaksanakan selama 16 kali pertemuan terbukti berhasil memberikan pengaruh terhadap peningkatan servis atas siswi ekstrakurikuler bola voli di SMPN 08 Kota Bengkulu. Seperti yang dikatakan (Apta dan Febi, 2015:47). Selain itu 
meningkatkan kemampuan servis atas harus ditunjang dengan potensi latihan yang terus menerus dan tetap melakukan pembelajaran servis atas dalam permainan bola voli. pembelajran yang kontinyu secara otomatis akan meningkatkan intensitas latihan, yang mana dengan intensitas latihan banyak membiasakan siswi dalam melakukan servis. Latihan yang terus menerus menjadikan pemain mampu mengetahui kesalahan-kesalahan yang dibuat dalam servis, sehingga dengan demikian dapat diperbaiki yang mana menjadikan servis akan semakin baik.

Berdasarkan hasil penelitian diatas diperoleh nilai thitung $17,7053>\mathrm{t}$ tabel $=1,699$. Hasil tersebut diartikan latihan beban botol berpasir berpengaruh terhadap hasil kemampuan servis atas pada siwi peserta ekstrakurikuler bola voli di SMPN 08 Kota Bengkulu. Pengaruh tersebut ditunjukan dengan meningkatnya kemampuan servis atas sebesar 3,4. Peningkatan bernilai positif artinya hasil servis atas setelah diberi metode beban botol berpasir menjadi lebih baik.

\section{PENUTUP}

\section{Simpulan}

Dari hasil thitung 17,7053 lebih > $t_{\text {tabel }} 1,699$. Maka data hasil pretest dan posttest dinyatakan signifikan. Dengan demikan hipotesis yang berbunyi "Ada pengaruh latihan beban botol berpasir terhadap kemampuan service atas siswi ekstrakurikuler bola voli di SMPN 8 Kota Bengkulu.

\section{Saran}

Dari kesimpulan penelitian di atas, ada beberapa saran yang dapat disampaikan yaitu :

1. Bagi anak yang mempunyai service atas yang masih kurang hendaknya dapat meningkatkan dengan latihan olahraga secara rutin dan dengan metode latihan beban.

2. Seorang pelatih di harapkan mampu menerapkan metode latihan yang efektif dengan merancang bentuk latihan yang baik agar diperoleh hasil latihan yang optimal, salah satunya dengan metode latihan beban

\section{DAFTAR PUSTAKA}

Anggoro, Turas Rio. (2016) Pengaruh Latihan Pembebanan Terhadap Power Tungkai Atlet Taekwondo Junior DIY.

Baechle, Thomas. Dan Barney R. Groves. (2009) Latihan Beban. Jakarta: PT Raja Grafindo Persada.

Basuki, Sunaryo, dkk (1976) ATLETIK (Latihan dan penyelenggaraan perlombaan). Jakarta: PT Pertja Offset.

Dian dan Bayu. (2013) Dasar-Dasar Penelitian Pendidikan Jasmani. FKIP Universitas Bengkulu.

Edwan, Ari, dan Bogy. 2017. "Pengaruh Metode Latihan Plyometric Terhadap Kemampuan Jumping Smash Bola Voli Siswa Ekstrakurikuler SMPN 1 Bermani Ilir Kabupaten Kepahiang" Jurnal Kinestetik, Vol. 1 (1)

Febrianti Rima (2016) Buku Ajar Tes dan Pengukuran. Universitas Tunas Pembangunan Surakarta.

Hidayat, Witono. (2017) Buku Pintar Bola Voli. Jakarta : Anugrah.

Kompri. (2016) Manajemen Pendidikan. Yogyakarta:AR-RUZZ MEDIA 
Mylsidayu, Apta dan Febi Kurniawan, (2015) Ilmu Kepelatihan Dasar. Bandung: Alfabeta.

Pardijono, dkk. (2011) Buku Ajar Bola Voli. Unesa University Press.

Pilda (2015) Skripsi. "Pengaruh latihan beban dumbbell terhadap kemampuan service float pada cabang olahraga bola voli di club porpu Bengkulu".

Sugiyono (2006) Metode Penelitian Kuantitatif Kualitatif dan $R \& D$. Bandung: Alfabeta.

Tangkudung, James. (2012). Kepelatihan Olahraga Pembinaan Prestasi Olahraga. Jakarta: Cerdas jaya . ,(2016).Macam-macam Metodologi Penelitian. Jakarta: Lensa Media Pustaka Indonesia. ,(2018). Sport Psychometrics Dasar-dasar dan instrument Psikometri. Depok :Rajagrafindo persada.

Tri Susanto (2017) Skripsi. “Meningkatkan kemampuan servis atas melalui penerapan latihan menggunakan beban dumbbell pada siswa kelas $X$ ips 6 SMA PLUS Negeri 7 Bengkulu".

Yoyo dan Adang (2000) prinsip-prinsip pengembangan dan modifikasi cabang olahraga. 